\begin{tabular}{|l|c|c|c|c|}
\hline Maced. J. Chem. Chem. Eng. & Vol. & No. & pp. & Skopje \\
\hline
\end{tabular}

\title{
MACEDONIAN JOURNAL OF CHEMISTRY AND CHEMICAL ENGINEERING
}

www.mjcce.org.mk

\section{EDITOR-IN-CHIEF}

Zoran Zdravkovski

Institute of Chemistry, Faculty of Natural Sciences and Mathematics, Ss. Cyril and Methodius University, 1001 Skopje, N. Macedonia Phone: (+389-2) 324-9926; e-mail: zoran@ukim.edu.mk

\section{EDITORIAL BOARD}

Marina Stefova, Deputy Editor-in-Chief, Skopje, N. Macedonia

Jadranka Blaževska-Gilev, Skopje, N. Macedonia

Aleksandra Buzarovska, Skopje, N. Macedonia

Angel Gil-Izquierdo, Murcia, Spain

Rubin Gulaboski, Štip, N. Macedonia

Kersti Hermansson, Uppsala, Sweden

Kiril Hristovski, Mesa, Arizona, USA

Ružica Jovanović-Malinovska, Skopje, N. Macedonia

Branko Kaitner, Zagreb, Croatia

Irina Karadjova, Sofia, Bulgaria

Ferenc Kilár, Pécs, Hungary

Petre Makreski, Skopje, N. Macedonia
Panče Naumov, Abu Dhabi, United Arab Emirates

Laszlo Nemes, Budapest, Hungary

Dobrin Nedelkov, Tempe, Arizona, USA

Franc Perdih, Ljubljana, Slovenia

Menka Petkovska, Belgrade, Serbia

Helena Pinheiro, Lisbon, Portugal

Walter Steiner, Graz, Austria

Levent Toppare, Ankara, Turkey

Borislav V. Toshev, Sofia, Bulgaria

Anka Trajkovska Petkoska, Veles, N. Macedonia

James Trefil, Fairfax, Virginia, USA
Jean Jacques Aaron, Paris, France

Maja Cvetkovska, Skopje, N. Macedonia

Svetomir Hadži-Jordanov, Skopje, N. Macedonia

Gligor Jovanovski, Skopje, N. Macedonia

Ivan Leban, Ljubljana, Slovenia

\section{ADVISORY BOARD}

Stanisław Slomkowski, Lódź, Poland

Trajče Stafilov, Skopje, N. Macedonia

Bojan Šoptrajanov, Skopje, N. Macedonia

Dimiter Tsalev, Sofia, Bulgaria

Eleonora Winkelhausen, Skopje, N. Macedonia

Published twice a year

Indexed in: Chemical Abstracts Service, Science Citation Index Expanded (SciSearch ${ }^{\circledR}$ ), Chemistry Citation Index ${ }^{\circledR}$, Journal Citation Reports/Science Edition, Directory of Open Access Journals (DOAJ), SCOPUS, Google Scholar, EBSCO, EVISA, etc

Technical editor: Sonja Malinovska; Cover: Ladislav Cvetkovski

English language adviser: Proof-Reading-Service.com; Macedonian language adviser: Georgi Georgievski; Proof-reader: Alena Georgievska

Publisher: Society of Chemists and Technologists of Macedonia, Arhimedova 5, Skopje, N. Macedonia

Printed by: Polyesterday, Skopje, N. Macedonia; Circulation: 50 copies; Price: 15 Euros

Printed in June 2019

Financed by the Ministry of Education and Science of the Republic of North Macedonia and Ss. Cyril and Methodius University

\section{МАКЕДОНСКО СПИСАНИЕ ЗА ХЕМИЈА И ХЕМИСКА ТЕХНОЛОГИЈА}

Зоран Здравковски, главен и одговорен уредник

Институт за хемија, Природно-математички факултет, Универзитет „Св. Кирил и Методиј“, 1001 Скопје, С. Македонија Тел.: (+389-2) 324-9926; е-адреса: zoran@ukim.edu.mk

Излегува два пати годишно

Издава: Сојуз на хемичарите и технолозите на Македонија, Архимедова 5, Скопје, С. Македонија

Печати: Polyesterday, Скопје, С. Македонија; Тираж: 50 примероци; Цена: 900 ден. Отпечатено, јуни 2019 